\title{
Equation of state of HE detonation products
}

\author{
B.A. Nadykto \\ RFNC-VNIIEF, Sarov, Nizhniy Novgorod Region 607190, Russia
}

\begin{abstract}
Computational analysis of steady-state HE detonation parameters is possible if one knows the equation of state of detonation products and thermal energy released at the Jouget point during detonation. There are a number of equations of state of $\mathrm{HE}$ detonation products that result from different assumptions concerning detonated material conditions. The paper considers one more version of the equation of state for HE detonation products.
\end{abstract}

\section{Introduction}

Parameters downstream of the detonation front are usually calculated using the conservation laws at the shock discontinuity based on the equation of state of detonation products and accounting for the conversion energy. Just as for inert materials, the energy and pressure are represented as a sum of elastic and thermal parts. The equation of state of HE detonation products is set up similarly to the equation of state of condensed inert materials [1-3]. In detonation products, rather large HE molecules are divided into small fragments, with $\mathrm{H}_{2} \mathrm{O}$ and $\mathrm{CO}_{2}$ constituting the larger fraction of them. Therefore, the equilibrium density of detonation products at $\mathrm{T}=0$ in the simulations is assumed to be equal to about $1.2 \mathrm{~g} / \mathrm{cm}^{3}$. In fact, the EoS parameters for detonation products are chosen such as to describe the largest possible set of experimental data, including the Jouget point parameters for different HE densities, unloading isentrope from the Jouget point, parameters of overdriven detonation and recompression of detonation products (detonation product deceleration curve).

The knowledge of the equation of state and caloric value of HE makes it possible to calculate the $D(\rho)$ curve behind the shock front. From the mass conservation law at the shock discontinuity, $\rho(D-u)=\rho_{0} D$, by differentiating with respect to $\rho$, we obtain the expression $(D-u)+\rho(d D / d \rho$ $-d u / d \rho)=\rho_{0} d D / d \rho$, which suggests that the condition of steady-state Chapman-Jouget detonation, $D=c+u$, means that the derivative $d D / d \rho$ is equal to zero. It follows from the Riemann invariants that $\rho d u / d \rho$ is equal to the speed of sound $c$ behind the wave front. Therefore, the detonation velocity is defined in the simulations as a minimum value of the shock velocity on the $D(\rho)$ curve.

\section{Equation of state of PETN detonation products}

References [4,5] presents rather detailed measurements of the detonation velocity of PETN with different initial densities. For PETN, we have chosen an equation of state of detonation products with $\rho_{\mathrm{o}}=1.22 \mathrm{~g} / \mathrm{cm}^{3} ; \mathrm{B}_{\mathrm{o}}=14.5 \mathrm{GPa}$ and $\mathrm{Q}=2.5 \mathrm{~kJ} / \mathrm{g}$, which describes the values of detonation velocity from Refs. [4,5] in the range of densities of $1.4-1.763 \mathrm{~g} / \mathrm{cm}^{3}$ to within about $1 \%$. The plot of $\mathrm{D}\left(\rho_{\mathrm{oo}}\right)$ is shown in Fig. 1 The simulation also quite accurately reproduces the curves of $\mathrm{D}(u)[6]$ and $\mathrm{P}(\rho)$ [7] for overdriven detonation (see Fig. 2 and Fig. 3).

This is an Open Access article distributed under the terms of the Creative Commons Attribution-Noncommercial License 3.0, which permits unrestricted use, distribution, and reproduction in any noncommercial medium, provided the original work is properly cited. 
$\mathrm{D}, \mathrm{km} / \mathrm{s}$

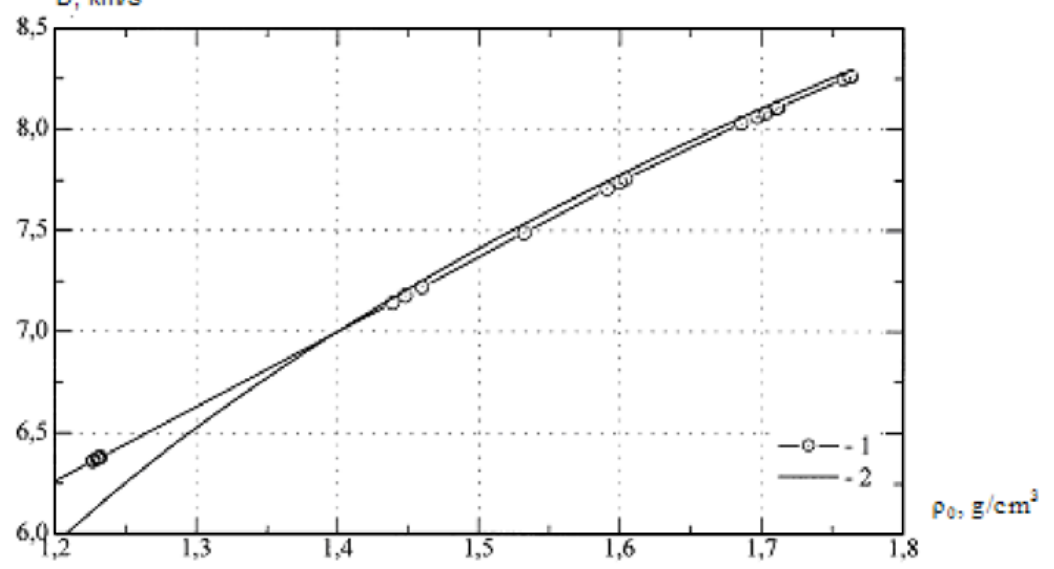

Fig. 1. The rate of normal detonation $D$ in PETN as a function of its initial density $\rho_{\mathrm{oo}} .1-$ experiment, 2 - calculations.

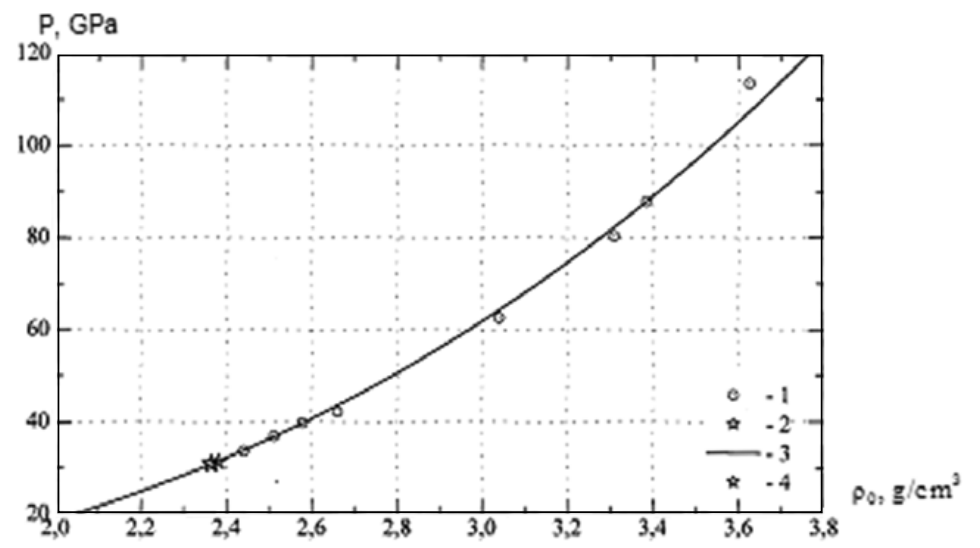

Fig. 2. The pressure of overdriven detonation in PETN having the initial density of $\rho_{\mathrm{oo}}=1.763 \mathrm{~g} / \mathrm{cm}^{3}$ as a function of downstream density. The curve represents calculations, and the points are from Ref. [7].

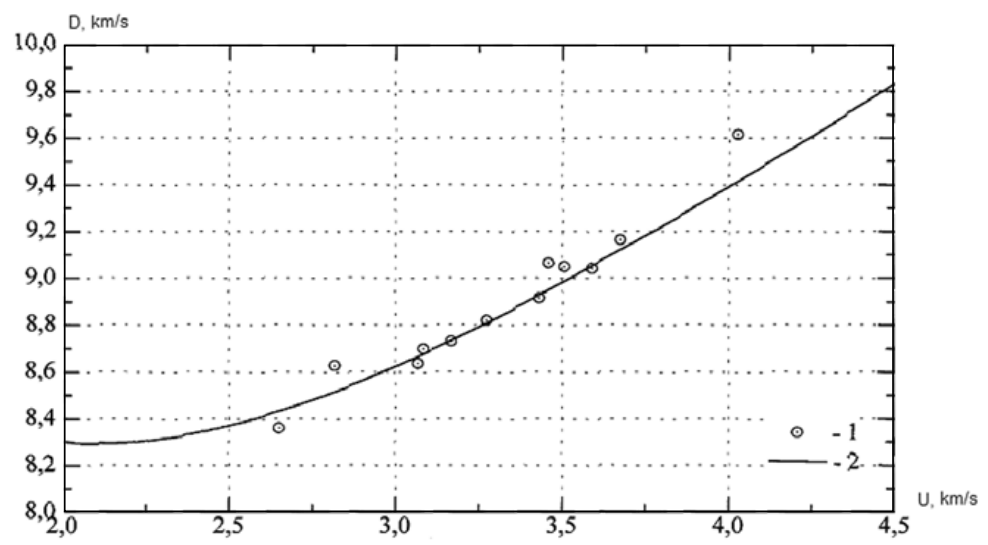

Fig. 3. The rate of overdriven detonation in TNT having the initial density of $\rho_{\mathrm{oo}}=1.763 \mathrm{~g} / \mathrm{cm}^{3}$ as a function of downstream mass velocity. The curve represents the calculations, and the points are from Ref. [6]. 


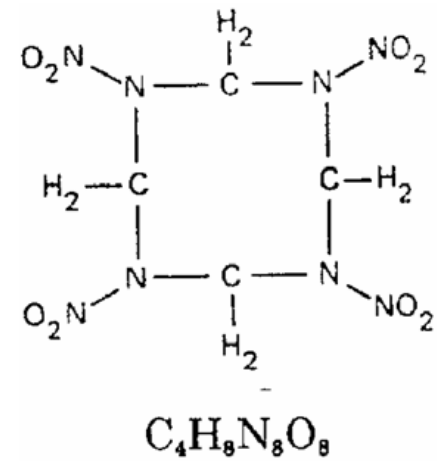<smiles>O=[N+]([O-])C1CN([N+](=O)[O-])CCN1[N+](=O)[O-]</smiles>

\section{$\mathrm{C}_{8} \mathrm{H}_{8} \mathrm{~N}_{8} \mathrm{O}_{8}$}

Fig. 4. Molecule structure of HMX (left) and RDX (right).

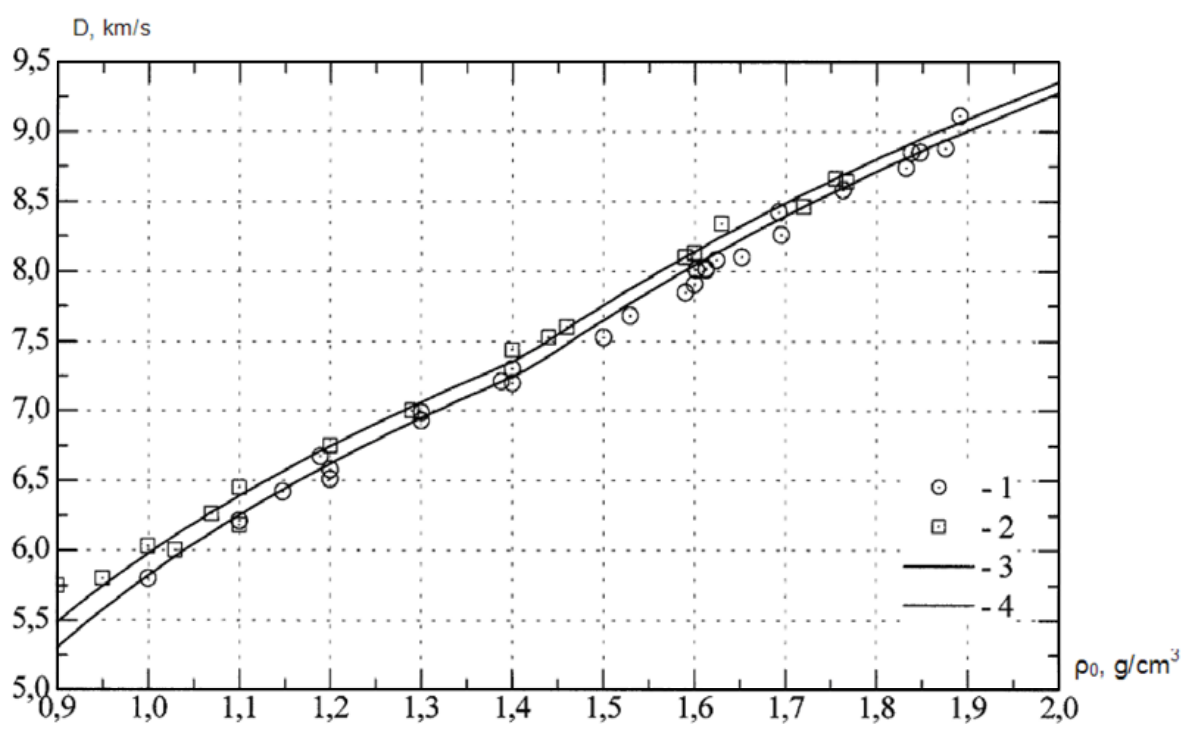

Fig. 5. Comparison of our calculated plots of detonation rates vs. initial density of HMX and RDX with experimental data. Experiment: circles are for HMX from Refs. [8,9], and squares are for RDX from Refs. [10-15]. The upper calculated curve is for RDX, and the lower one is for HMX.

\section{Equation of state of RDX and HMX detonation products}

RDX and HMX have the same chemical composition $\left(\mathrm{CH}_{2} \mathrm{~N}_{2} \mathrm{O}_{2}\right)$, but differ in the molecule structure (see Fig. 4) and density under normal conditions.

Reference [18] summarizes experimental data on the dependence of the detonation rate of HMX and RDX on the initial density of explosive and compares them with results calculated by Ree's equation of state. Experimental data for HMX were borrowed from Ref. [9], and for RDX, from Russian publications [10-15]. Our detonation calculations for RDX were performed with an equation of state of RDX detonation products defined in the form of two regions with the following parameters: $\rho_{\mathrm{o}}=1.05 \mathrm{~g} / \mathrm{cm}^{3} ; \mathrm{Bo}=9.7 \mathrm{GPa}\left(\right.$ region I), $\rho_{\mathrm{o}}=1.255 \mathrm{~g} / \mathrm{cm}^{3} ; \mathrm{Bo}=18.3 \mathrm{GPa}$ (region II) and caloric value of explosive $\mathrm{Q}=3.4 \mathrm{~kJ} / \mathrm{g}$. A comparison of our calculated results with experimental data of Ref. [8-15] for HMX and RDX is shown in Fig. 5. The calculations are in close agreement with the experimental data. For the equal initial density, the rate of detonation in RDX turns out to be somewhat higher than in HMX. For the high initial density, the difference in the detonation rate is $0.1 \mathrm{~km} / \mathrm{s}$, and for the $1 \mathrm{~g} / \mathrm{cm}^{3}$ density, the difference increases to $0.2 \mathrm{~km} / \mathrm{s}$. Calculations for RDX were performed with the same equation of state of detonation products, as for HMX, but with a small increase in the 


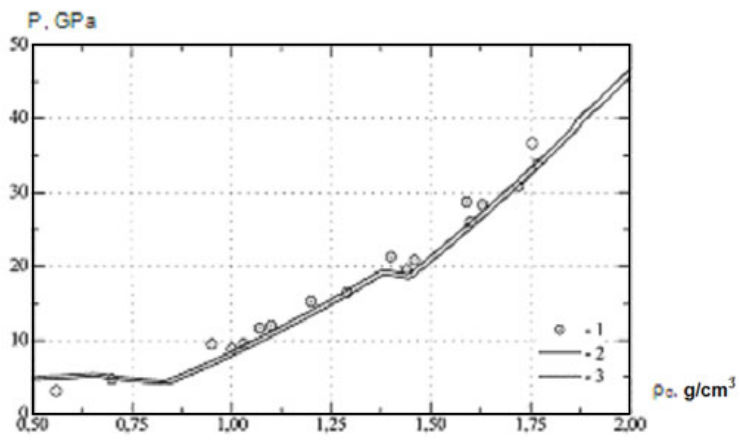

Fig. 6. Jouget pressure as a function of initial Jouget density. Experiment: circles are for RDX from Refs. [8,10-15]. The upper calculated curve is for RDX, and the lower one is for HMX.

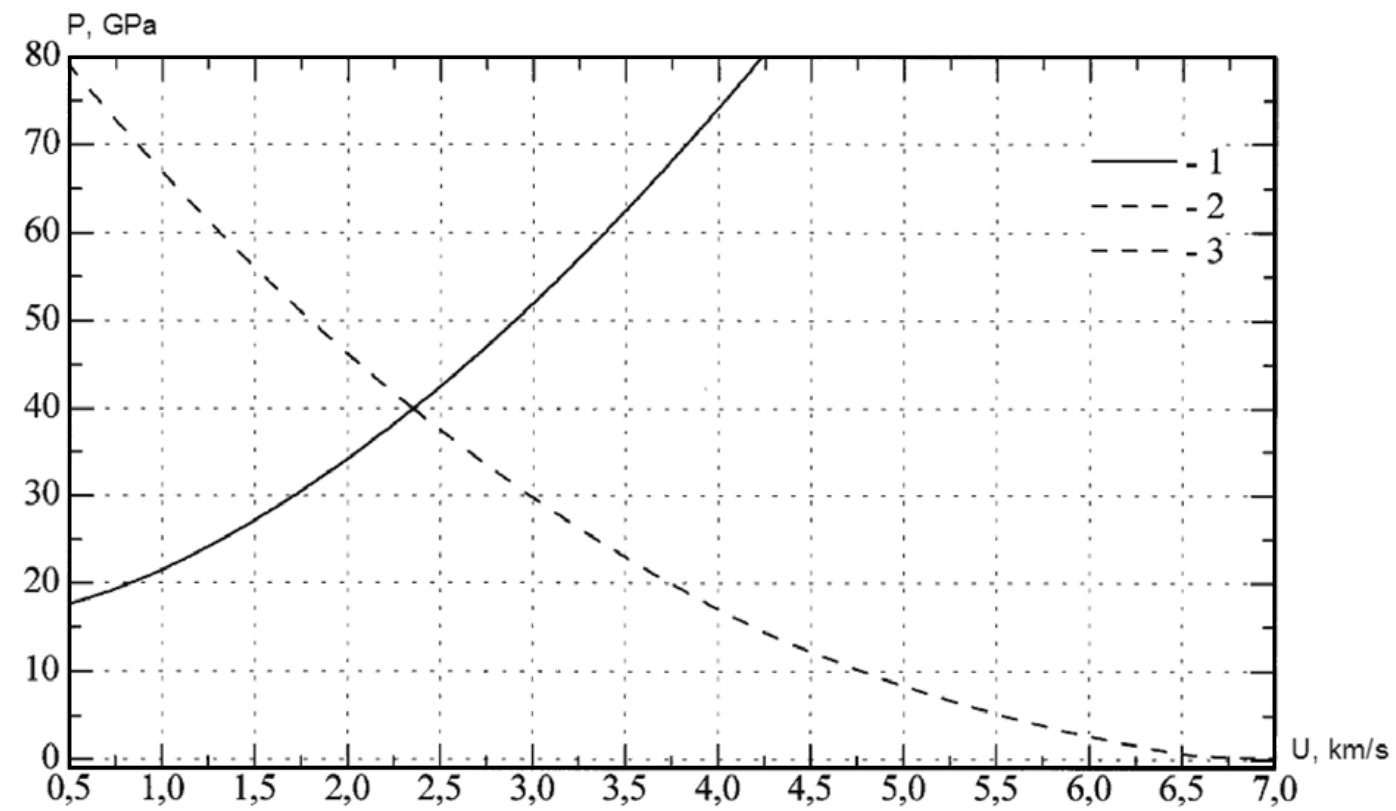

Fig. 7. Pressure as a function of mass velocity for shock-compressed HMX detonation products for the initial density of $1.891 \mathrm{~g} / \mathrm{cm}^{3}$ on the expansion isentrope and under repeated compression from the Jouget point.

caloric value to $3.7 \mathrm{~kJ} / \mathrm{g}$. The calculated values of the normal detonation rate in HMX and Jouget pressure for the initial density of explosive of $\rho \mathrm{o}=1.891 \mathrm{~g} / \mathrm{cm}^{3}$ are $\mathrm{D}=8.98 \mathrm{~km} / \mathrm{s}$ and $\mathrm{P}=39.96 \mathrm{GPa}$. The experimental data from Ref. [17] are $\mathrm{D}=9.11 \mathrm{~km} / \mathrm{s}$ and $\mathrm{P}=39.5 \mathrm{GPa}$, respectively. The calculation/experiment discrepancy is about $1 \%$. For RDX of initial density $\rho_{\mathrm{o}}=1.767 \mathrm{~g} / \mathrm{cm}^{3}$, these values are $\mathrm{D}=8.6 \mathrm{~km} / \mathrm{s}$ and $\mathrm{P}=34 \mathrm{GPa}$. The experimental values from Ref. [17] are $\mathrm{D}=8.64 \mathrm{~km} / \mathrm{s}$ and $\mathrm{P}=33.79 \mathrm{GPa}$, respectively.

Paper [18], with reference to [10-15], presents Jouget pressure values measured in RDX of different initial densities. Figures 6-18 show a comparison of these data with our calculated values. The comparison shows that the calculated curve for RDX is in close agreement with the measured data. The calculated pressure in HMX for the same density of explosive is 2-3\% lower than in RDX.

Figure 7 shows the plots of pressure as a function of mass velocity for shock-compressed HMX detonation products for the initial density of $1.891 \mathrm{~g} / \mathrm{cm}^{3}$ on the expansion isentrope and under repeated compression from the Jouget point. The calculated Jouget parameters $(\mathrm{D}=8.98 \mathrm{~km} / \mathrm{s}$, $\mathrm{u}=2.35 \mathrm{~km} / \mathrm{s}, \mathrm{P}=39.96 \mathrm{GPa}$ ) agree with the experimental data to within $\sim 1 \%$ [17]. 


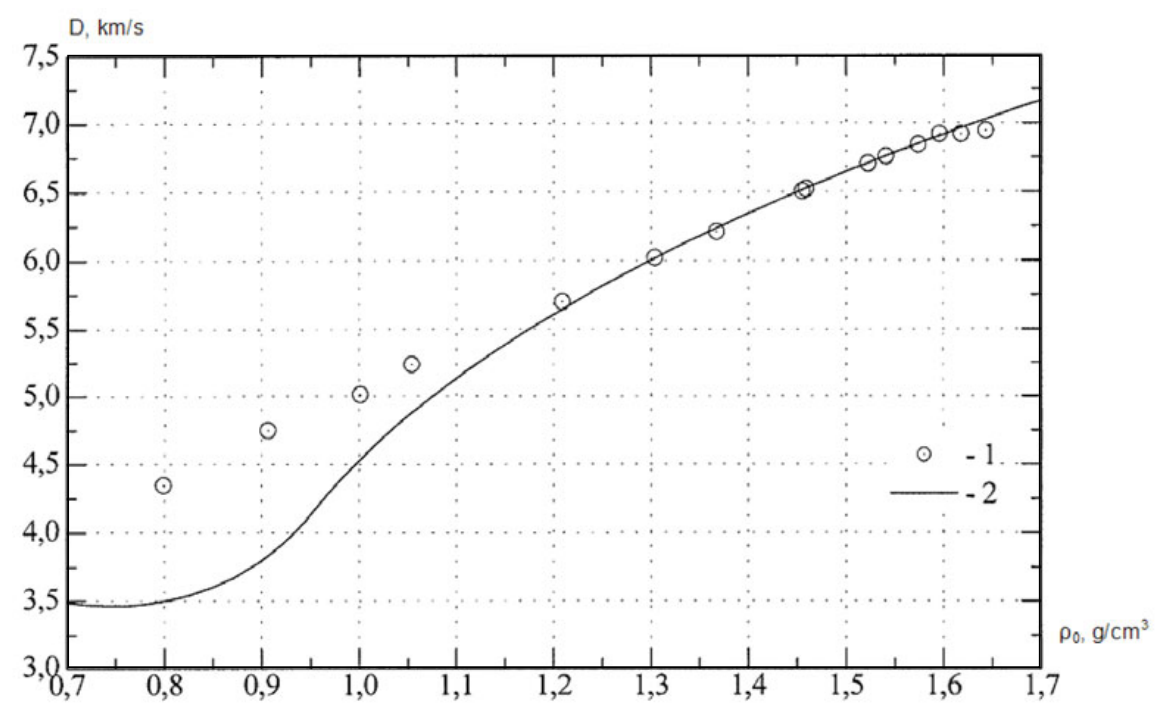

Fig. 8. Comparison of our calculated plots of detonation rates vs. initial density of TNT with experimental data. Experiment: circles are from Ref. [17]. The curve represents the calculated data.

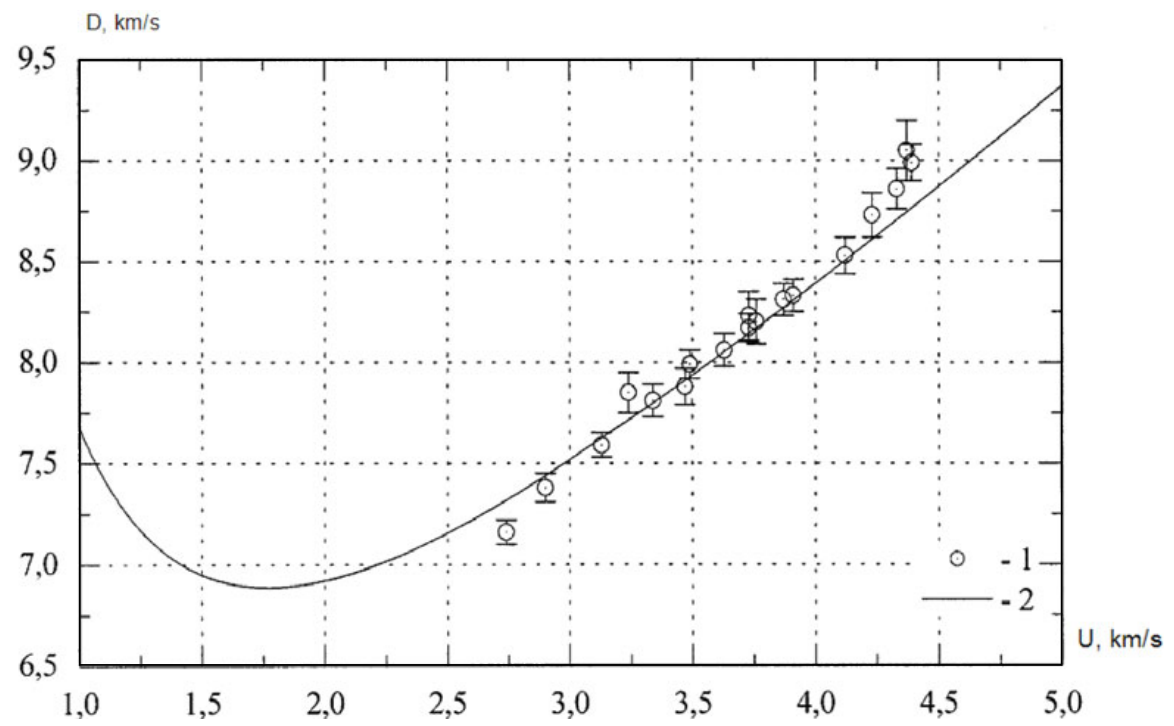

Fig. 9. The plot of the rate of overdriven detonation in TNT having the initial density of $\rho_{\mathrm{oo}}=1.588 \mathrm{~g} / \mathrm{cm}^{3}$ as a function of downstream mass velocity. The curve represents the calculations, and the points are from Ref. [17].

\section{Equation of state of TNT detonation products}

Reference [16] summarizes experimental data on the dependence of the detonation rate in TNT on its initial density. For TNT, we have chosen an equation of state of detonation products with $\rho_{\mathrm{o}}=$ $1.12 \mathrm{~g} / \mathrm{cm}^{3} ; \mathrm{B}_{\mathrm{o}}=10 \mathrm{GPa}$ and $\mathrm{Q}=2.0 \mathrm{~kJ} / \mathrm{g}$, which describes the values of detonation velocity from Ref. [16] in the range of densities of $1.2-1.64 \mathrm{~g} / \mathrm{cm}^{3}$ to within about $1-2 \%$. According to Ref. [17], the rate of normal detonation in TNT with $\rho_{\mathrm{o}}=1.62-1.64 \mathrm{~g} / \mathrm{cm}^{3}$ is $6.94-7.04 \mathrm{~km} / \mathrm{s}$. Our calculations with the aforementioned parameters give $\mathrm{D}=7.0 \mathrm{~km} / \mathrm{s}$. The plot of $\mathrm{D}\left(\rho_{\mathrm{oo}}\right)$ is shown in Fig. 8 .

Reference [8] contains measured parameters of overdriven detonation in cast TNT with $\rho_{\mathrm{o}}=$ $1.588 \mathrm{~g} / \mathrm{cm}^{3}$ in the pressure range of 30-60 GPa. Figures 9-10 show a comparison of calculated overdriven detonation parameters with the data of Ref. [8]. One can see that the calculations are in close 


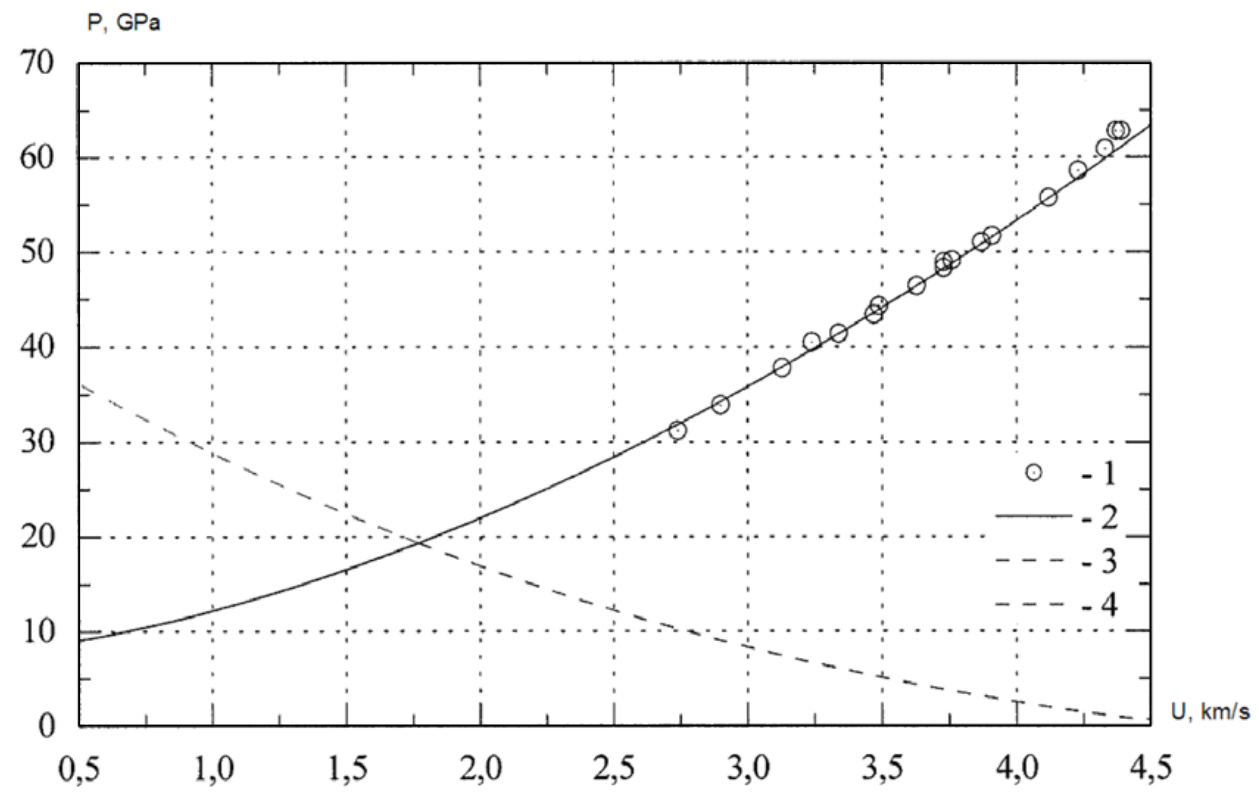

Fig. 10. Pressure as a function of mass velocity for shock-compressed TNT detonation products for the initial density of $1.588 \mathrm{~g} / \mathrm{cm}^{3}$ on the expansion isentrope and under repeated compression from the Jouget point.

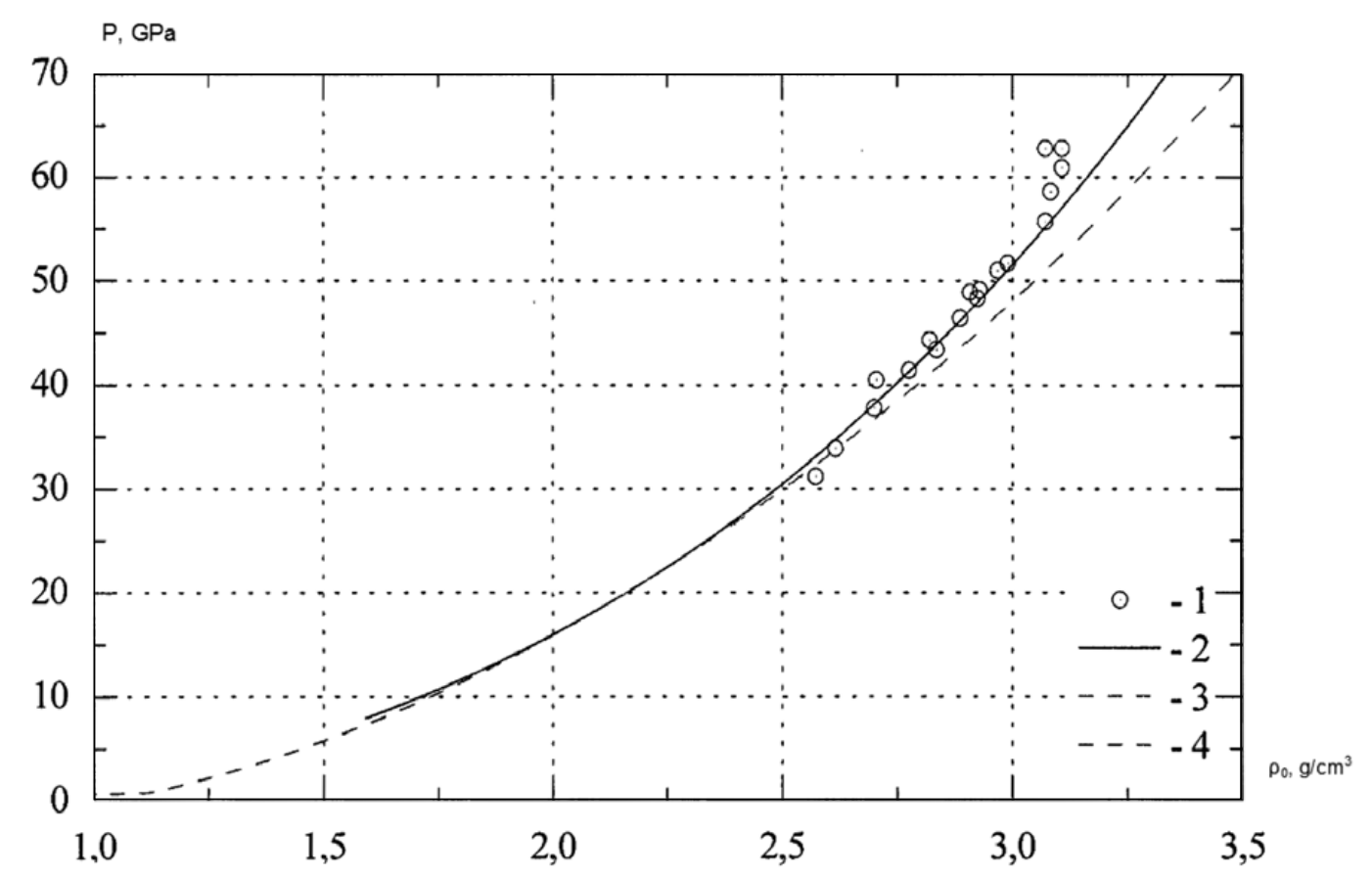

Fig. 11. Pressure as a function of density downstream of the detonation front in TNT having the initial density of $1.588 \mathrm{~g} / \mathrm{cm}^{3}$ and during relief from the Jouget point. The experimental data for overdriven detonation in TNT are from Ref. [17].

agreement with the experimental data in the D-u (Fig. 9), P-u (Fig. 10) and P- $\rho$ (Fig. 11) coordinates. As in case of PETN, RDX and HMX, the parameters of the equation of state for detonation products, which describe the rate of normal detonation as a function of initial density of explosive, provide a correct description of overdriven detonation parameters. 
Equations of state of detonation products for other pure and mixed explosives are set up analogously.

\section{Conclusions}

1. The equation of state of detonation products in the Mie-Grueneisen approximation, which represents the pressure and energy as a sum of the elstic (cold) and thermal components, provides a correct description of the parameters of normal and overdriven detonation, expansion isentrope and repeated shock compression.

2. Fitting of equation-of-state parameters for detonation products based on the description of the dependence of normal detonation velocity on the initial density of explosive provides a good description of other detonation and expansion isentrope parameters.

\section{References}

1. B.A. Nadykto, Physics-Uspekhi, 36, 794, (1993)

2. B.A. Nadykto, VANT. Ser.: Theoretical and Applied Physics, 3, 58 (1996)

3. B.A. Nadykto, Advances in Material Science. Edited by D. Kusnezov, O.N. Shubin, V-9, (2009)

4. L.G. Green, E.L. Lee. 13-th International Detonation Symposium. July 23-28, 1144 (2006)

5. H.C. Hornig, E.L. Lee, M. Finger, J.E. Kurrle. 5-th International Detonation Symposium. Aug. 18-21, 503, (1970)

6. E.L. Lee, M. Van Thiel, L.G. Green, A. Mitchell. Shock Wave in Condensed Matter, XIII-9, (1983)

7. M. Van Thiel, F.H. Ree, L.C. Haselman. 10-th International Detonation Symposium. July 12-16, 425 (1993)

8. D.J. Steinberg. 8-th International Detonation Symposium. July 15-19, 513 (1985)

9. J. Kurrle. HMX Detonation vs Density. Report OSAO No 4148. SANL No 901-003, (1971)

10. N.M. Kuznetsov, K.K. Shvedov. Combustion, Explosion and Shock Waves. 2(4), 52, (1966)

11. A.N. Dremin, P.F. Pokhil. Acad. of Sciences, USSR, Proceedings, Phys. Chem. Section, 128, 839, (1959)

12. L.N. Stesik, L.N. Akimova. Journal of Physical Chemistry 33(8), 148, (1959)

13. L.N. Stesik, N.S. Shvedova. Journal of Appl. Mechanics and Engineering Physics. 4, 124, (1964)

14. A.L. Krivchenko, K.K. Shvedov, A.N. Dremin, V.S. Kozlov. Combustion, Explosion and Shock Waves. 8(4), 377, (1972)

15. E.N. Aleksandrov, V.A. Veretennikov, K.K. Shvedov, A.N. Dremin. Combustion, Explosion and Shock Waves. 3(4), 285, (1967)

16. K. Tanaka. 8-th International Detonation Symposium. July 15-19, 548, (1985)

17. C.L. Mader et al. LASL EXPLOSIVE PROPERTY DATA. University California Press, Berkeley and Los Angeles, Califirnia. (1980)

18. Kineke J.H., West C.E. 5-th International Detonation Symposium. Aug. 18-21, 533 (1970) 